\title{
Which Factors Influence a Company's Evaluation of the Contribution of Basic Research to Innovation?
}

\author{
Hiromi S. Nagane \& Koichi Sumikura
}

\author{
" Progress in the war against disease depends upon a flow of new scientific \\ knowledge. New products, new industries, and more jobs require continuous \\ additions to knowledge of the laws of nature, and the application of that \\ knowledge to practical purposes." \\ Vannevar Bush \\ Director of the Office of Scientific Research and Development
}

\begin{abstract}
This paper empirically analyses how individuals in companies evaluate the contributions of basic research by universities and public research institutes to industry from multiple perspectives: manager as a spokesperson of the company (science-based industry or others), position within the company (managers or inventors), affiliations of inventors (large pharmaceutical companies or biotech start-ups), and educational background. This paper focuses on the case of Japan. Questionnaire surveys were sent to managers and inventors in established companies and startups across several industries. This study found that, 1) the more science-oriented the company, the higher their managers evaluate academic research, 2) inventors evaluate academic research more highly than managers, 3) inventors from biotech start-ups evaluate academic research more highly than inventors from large companies in the pharmaceutical industry, and 4) the more advanced their educational background, the more highly inventors evaluate academic research. This study suggests that 'closeness to science' is an important factor for companies to evaluate contributions of basic research to innovation. The findings also suggest that problems within the current educational system are an indirect cause of the innovation crisis in Japan.
\end{abstract}

\section{Introduction}

Basic research is the fountainhead of innovation. Basic research is defined as an experimental or theoretical work undertaken primarily to acquire new knowledge of the underlying foundations of phenomena and observable facts, without any particular application or use in view (OECD, 2002). Breakthrough discoveries made in basic research have led to the creation of many unique technologies. For example, Nobel Prize-winning research has proposed innovative technologies that improve our lives and society. The outcomes of basic research are crucial for science-based industries, including applied fields like the pharmaceutical industry.

Basic research is rarely conducted voluntarily in the marketplace. Yet knowledge produced by basic research satisfies both non-exclusivity and non-rivalry as a public good. First, once a public good is made available, users cannot be prohibited from using it, even if property rights have not yet been clearly defined, thus guaranteeing non-exclusivity. Second, knowledge is non-rivalrous in that once generated, it is neither depleted nor diminished by use. It imparts significant benefits to society, yet the company that conducted the relevant basic research cannot monopolize it, despite their having made a substantial investment in producing knowledge. Companies therefore have less incentive to conduct basic research voluntarily. Furthermore, basic research can be subject to great uncertainty, and the potential outcomes of new technology and product development are often difficult or impossible to predict. Consequently, basic research often constitutes a highrisk investment for private companies, which cannot justify focus on conducting basic research simply based on having strong financial power. 


\section{Which Factors Influence a Company's Evaluation of the Contribution of Basic Research to Innovation? Hiromi S. Nagane \& Koichi Sumikura}

Some private companies around the world have taken the initiative to conduct basic research due to financial luxury or business need. However, the private basic research sector has shrunk significantly, for example, in the United States, as managers consider the role of research laboratories of companies conducting basic research to be shrinking in importance (Rosenbloom \& Spencer, 1996). There is a similar situation in Japan, which is the national case study for this paper. Although private companies in Japan have long conducted basic research, many companies have reviewed research laboratories of companies and decreased their association with them owing to poor performance.

Private companies have recently begun to introduce and employ external research units, giving rise to a trend of 'open innovation' (Chesbrough, 2003, 2006). Universities and public research institutes in Japan are important external providers of basic research outcomes to private companies. They can conduct research independent of market mechanisms by taking public funding to conduct research.

However, universities and public research institutes are shrinking in Japan. Until 2019, Japan ranked sixth in number of Nobel Prize winners. However, the number of Japanese academic papers is declining, including its share in the total number of papers and top cited papers (NISTEP, 2019). Many scientists, including Nobel Prize winners, have warned of a crisis in the basic science sector in Japan.

It is important to understand how basic research by universities and public research institutes contributes to industry and society. Innovation will not be promoted if companies do not use the newest knowledge acquired through basic research conducted by universities and public research institutes. We should therefore adequately evaluate and explain the contribution of basic research outcomes by universities and public research institutes as a way to promote knowledge transfer from these organisations to industry. This is what leads to the question we arrived at for this research and for the paper's title: which factors influence $a$ company's evaluation of the contribution of basic research to innovation?

It is difficult to assess the extent to which research outcomes from universities and public institutions contribute to industry. The dissemination of basic research takes various routes, and it is therefore difficult to predict or to trace spillover of outcomes and knowledge into industry. Nevertheless, ev/idence-based analysis is required for knowledge management and policy planning. Evidence-based policy is manifested as a global trend known as the 'science of science policy' (Jaffe, 2006), which emphasizes the importance of quantitative methodologies, including econometrics. An evidence-based approach is also important for companies to formulate management strategy. Many countries share this issue and reconsider their understanding on how academic research impacts industry. Thus, there is a need for more research that could contribute to examining the relationship between academic research and its impacts on industries.

The present study empirically analyses the degree to which individuals on the side of industries evaluate the need for research outcomes from universities and public research institutes in industrial applications. It does this from multiple perspectives: manager as a company spokesperson among different industries (science-based industries or others), various positions within an industry (managers and inventors), affiliations of inventors (large pharmaceutical companies or biotech start-ups), and educational background of inventors.

\section{Research Insights from Existing Literature}

Both objective and subjective data can be employed to quantitatively analyse the ways in which scientific knowledge from academic research is absorbed and used. Academic papers and patent data are often considered representative objective data. Narin and colleagues (1997), for example, focused on papers cited in patents, showing that approximately $75 \%$ of papers cited in corporate patents in the United States were based on public research.

McMillan and colleagues (2000) also analysed U.S. biotechnology IPO companies based on patent references, indicating that this industry depends much more heavily on publicly produced science than other types of industry. Furthermore, some studies have analysed co-author status in printed publications to investigate how relationships between academic and corporate researchers affect pharmaceutical companies' performance. Cockburn and Henderson (1997) focused on scientific papers co-authored by publicly funded and pharmaceutical company researchers, and showed that the proportion of co-authorship with universities correlated with the companies' research performance in drug discovery, as indicated by several important patents granted per research dollar. Such findings 


\section{Which Factors Influence a Company's Evaluation of the Contribution of Basic Research to Innovation? Hiromi S. Nagane \& Koichi Sumikura}

indicate the importance of companies maintaining close connections with the upstream scientific community.

Zucker and Darby (2001) analysed research papers coauthored by celebrated university scientists together with Japanese company researchers in biotechnology, and showed that such collaboration improved companies' patent productivity by $34 \%$, product development by $27 \%$, and product commercialisation by 8\%. Zucker and colleagues (2002) also analysed the number of research articles written jointly by company scientists and leading scientists in biotechnology, most of whom were working at top universities, as an indicator of companies' tacit knowledge capture from academia. They used panel data to show that copublications by company scientists and leading scientists and/or scientists in the top 112 US research universities served to increase the number and citation rate of company patents. They also found that articles published jointly with leading scientists increased these rates significantly more than articles co-authored with the top 112 university scientists. Zucker and Darby (2007) also analysed changes in the performance of biotechnology leaders with relationships to start-ups, who have co-authored papers with start-ups, or held positions in start-ups. They showed that leading scientists who both held positions in start-ups and coauthored joint papers with them had significantly higher numbers of citations than leading scientists who only co-authored joint papers with start-ups. Zucker and Darby (2007) suggest the so-called 'virtuous circles in science and commerce', where scientists can improve their research achievements, and companies can enhance their corporate performance when leading scientists and companies are involved in some way. For example, the study by Zucker and Darby found that 35\% of leading bioscientists were involved with companies in commercialising their discoveries in the United States and Japan.

Another study focused on the patents themselves, specifically, the number of partner pharmaceutical companies that jointly applied for patents (Saito \& Sumikura, 2010a), and promoted indexing the amount of scientific knowledge companies assimilate from universities and public research institutes. The index the created was used to verify whether the acquisition of scientific knowledge influences corporate performance. The authors showed that the index was positively significant for patent application and patent propensity, but not significant for the number of approved drugs, implying that scientific knowledge assimilated from academia is effective for boosting technological performance in pharmaceutical companies.

However, such an index of objective data does not adequately explain the effects of basic research on industry. The papers and patents used as data by previous studies are considered as the 'outcome of successful research'. Research, however, is known to not always succeed. It may not produce results like papers and patents. However, it also demonstrates that 'failure teaches success'.

Our research found that companies absorb knowledge from universities and public research institutes in diverse ways that are broadly distributed. FernandezEsquinas and colleagues (2016) listed the following types of interaction between companies and universities: informal networks, in-company training of university postgraduates and internships, joint research and development (R\&D) projects, consultancy work, training of company workers by the university, $R \& D$ projects commissioned from universities, use or rental of facilities, exchanges of personnel, patent exploitation, participation in spin-offs and start-ups, joint ventures with universities, and other types of collaborative activities (types listed in order of \% of respondents answering 'yes'). De Fuentes and Dutreint (2016) listed channels of public research organization-industry interaction accordingly: publications, conferences, informal information, training (grouped as 'information and training'), hiring of recent graduates (grouped as 'human resources'), contract $R \& D$, joint $R \& D$, consultancy (grouped as 'R\&D projects and consultancy'), technology licenses and patents (grouped as 'intellectual property rights'). Most of the research paths on information, training, and human resources are not supposed to produce measurable outputs.

Fig. 1 categorises the knowledge paths from universities and public research institutes to companies based on broadness of scope. Previous works have resulted injoint papers or patents, with academia as indicators of these knowledge paths (Fig. 1-1). Papers and patents are the outcomes of successful research. If the research trajectories fail, then papers and patents do not appear. Industry-academia collaboration such as joint research (Fig. 1-2) facilitates knowledge flow, even if the research does not produce papers or patents, thus indicating a more formal relation. When contracts between companies and academia exist, the relation can be captured visually. However, it is difficult to capture the informal relations depicted at the base of the pyramid in 


\section{Which Factors Influence a Company's Evaluation of the Contribution of Basic Research to Innovation? Hiromi S. Nagane \& Koichi Sumikura}

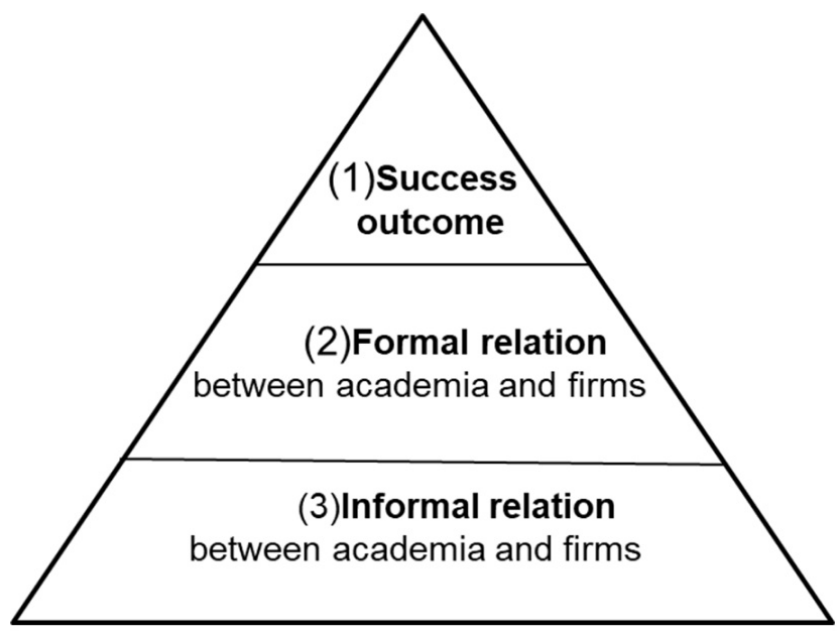

Figure 1. Categories of knowledge paths from universities and public research institutes to industry

Fig. 1-3, since companies can also absorb scientific knowledge from academic research through informal contacts with academia, such as at conferences or symposiums, and in personal exchanges.

Therefore, if we evaluate the contribution of academic knowledge to industry using only information that can be visually captured, it runs the risk that knowledge derived via informal routes may be overlooked.

As previously mentioned, the biotech/pharmaceutical industry has been shown to have great proximity to basic research. According to Stevens and colleagues (2011), 153 of the vaccine and drug products that received U.S. Food and Drug Administration (FDA) approval over the past 40 years were developed through public academic research activities. Notably, biotech/pharma products were not limited to vaccines and drugs. Relevant subjective information can also be useful for grasping the extent to which academic research contributes to a company's products and can be obtained through methods such as questionnaires or interviews.

Mansfield (1991, 1998) randomly sampled major American companies to determine the number of products that could not have been developed without the outcomes of basic research. Using an adapted questionnaire survey following Mansfield (1991, 1998), we applied this inquiry to Japanese companies to analyse how industry representatives in Japan evaluate the contribution of academic research outcomes. Unlike Mansfield, we asked not only managers, but also inventors in private companies.

\section{Research Method}

The objective of this study is to analyse how companies evaluate the contributions of basic research to industry from multiple perspectives empirically. We used data from two surveys conducted with different industry respondents: (1) management staff or operations staff in Japanese companies in all fields, and (2) inventors in pharmaceutical companies and biotech start-ups.

\section{Survey for company managers}

For survey (1), we designed our questionnaire according to Mansfield $(1991,1998)$ and delegated the survey conducting task to the research company, Teikoku Databank (TDB). TDB has associations with many companies in all industry types in Japan. The survey was conducted over 20 days, from December 17, 2008 to January 5, 2009. Questionnaires were sent via email to 20,455 companies, of which 10,731 provided effective answers (response rate of 52.5\%). Questionnaires were directed to management staff or divisions (hereafter, 'management' also refers to administrative staff, unless otherwise specified). We regarded managers as spokespersons of their companies. Saito and Sumikura (2010b) explain the survey procedure and descriptive statistics of this data in detail.

\section{Survey for company inventors}

In survey (2), we focused on inventors engaged in $R \& D$ activities with large pharmaceutical companies and biotech start-ups in Japan. Survey (2) was conducted because we found great differences in the responses to survey (1) by industry, especially between science-based 


\section{Which Factors Influence a Company's Evaluation of the Contribution of Basic Research to Innovation? Hiromi S. Nagane \& Koichi Sumikura}

Table 1. Definitions and descriptive statistics for the inventor survey

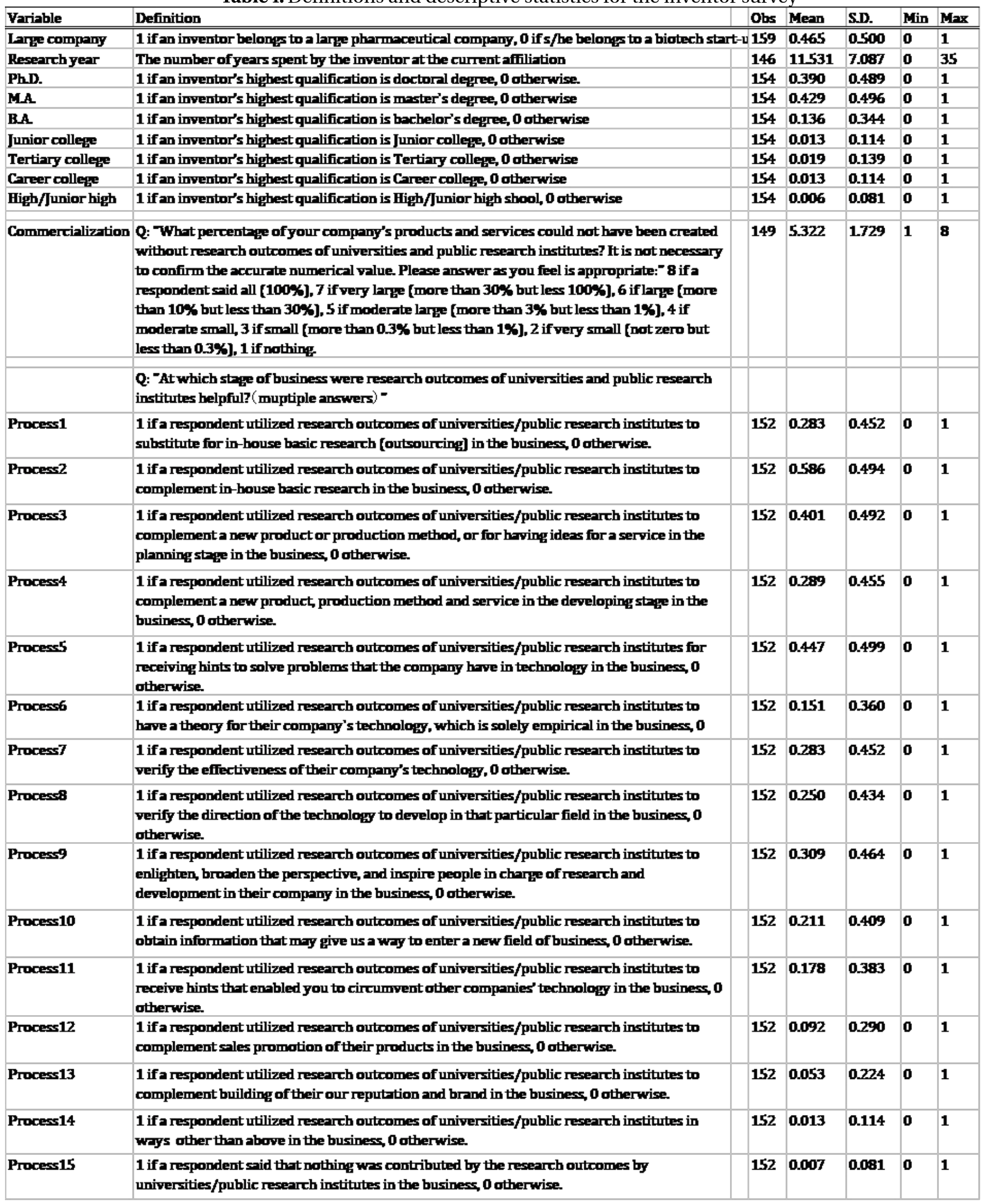




\section{Which Factors Influence a Company's Evaluation of the Contribution of Basic Research to Innovation? Hiromi S. Nagane \& Koichi Sumikura}

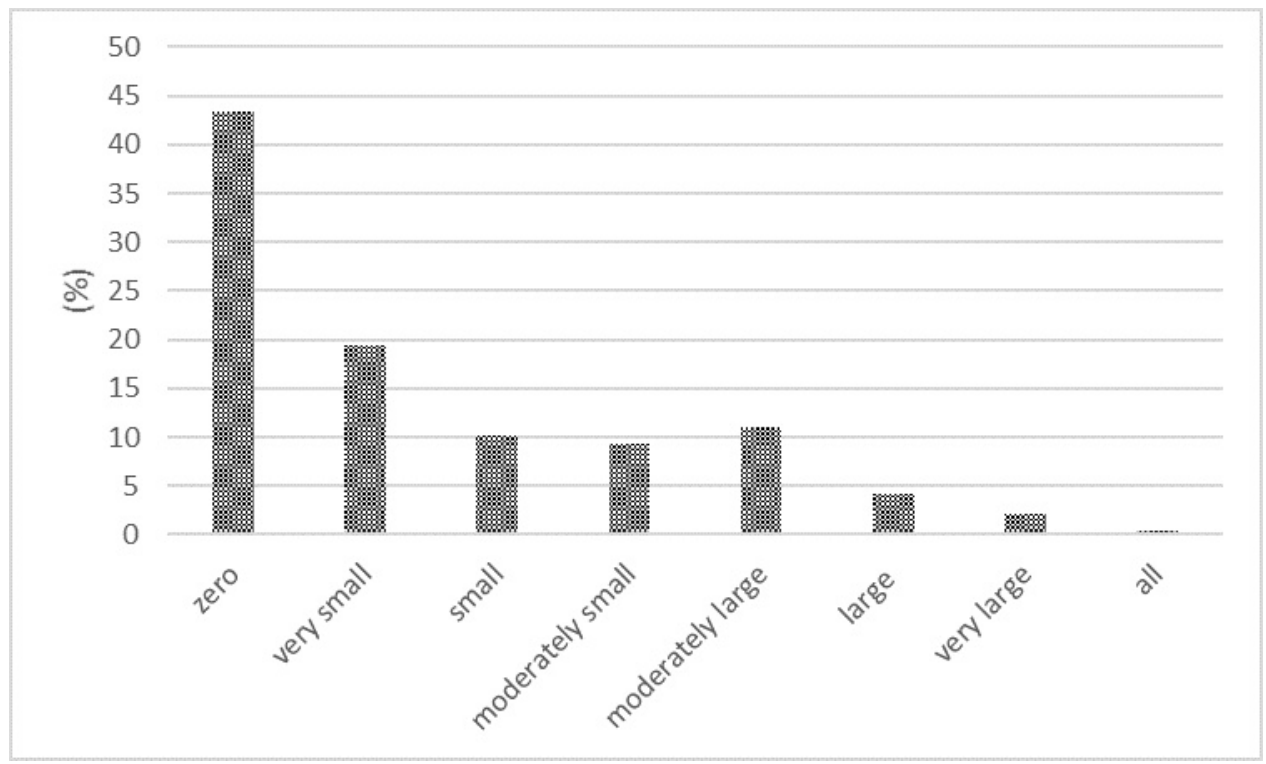

Figure 2. Percentage of products that could not have been developed without research outcomes from universities and public research institutes

Firms in all industries: $\mathrm{N}=5,173$

Source: Saito \& Sumikura (2010b), Fig. 19

industries and other industries. We selected inventors named in important patents, the 10 best-selling companies in 2008 (excluding foreign companies) based on IMS pharmaceutical market statistics, and the 23 companies listed in September 2009 as biotech start-ups in Japan.

As random sampling in this study may result in the inclusion of low-value patents, therefore, using the patents applied for after 2005, we conducted purposive sampling to ensure subjects were included based on the importance of their patents. For this purpose, we used Patent Score, an index used to extract important patents by Patent Result Co. Note that the inventors in this survey did not necessarily belong to the selected companies.

We selected the top 15 inventors in the Patent Score index from among each company's patent applications after 2005. For each large pharmaceutical company, 15 inventors were selected. After excluding two inventors residing abroad, the total number of inventors was 148 . A similar approach was used to select biotech start-up inventors. For biotech start-ups that had fewer than 15 inventors after 2005, as many inventors as possible were extracted, and the total number of biotech start-up inventors was 184. Questionnaires were sent to all 332 inventors. Of these, questionnaires sent to six inventors from large companies and 23 from biotech start-ups were returned because of incorrect addresses. The initial investigation period was December 1-18, 2009. However, respondents were also prompted to return questionnaires after the deadline. The final analysed sample was comprised of 160 respondents (response rate of $48 \%$ ), including inventors from 74 large companies and 85 biotech start-ups. The company type of one respondent was unknown.

Table 1 provides the definitions and descriptive statistics of the sample. The number of observations for both large company inventors and biotech start-up inventors is identical. The mean number of years inventors spent on research was about 11.5, and most respondents (42.9\%) held a master's degree (M.A.).

\section{Summary of Results}

How do managers evaluate the contribution of academic research outcomes?

Following Mansfield (1991, 1998), we asked managers what percentage of their products they would not have been able to develop without the research outcomes generated by universities and public research institutes. The questionnaire provided eight alternatives: all 


\section{Which Factors Influence a Company's Evaluation of the Contribution of Basic Research to Innovation? Hiromi S. Nagane \& Koichi Sumikura}

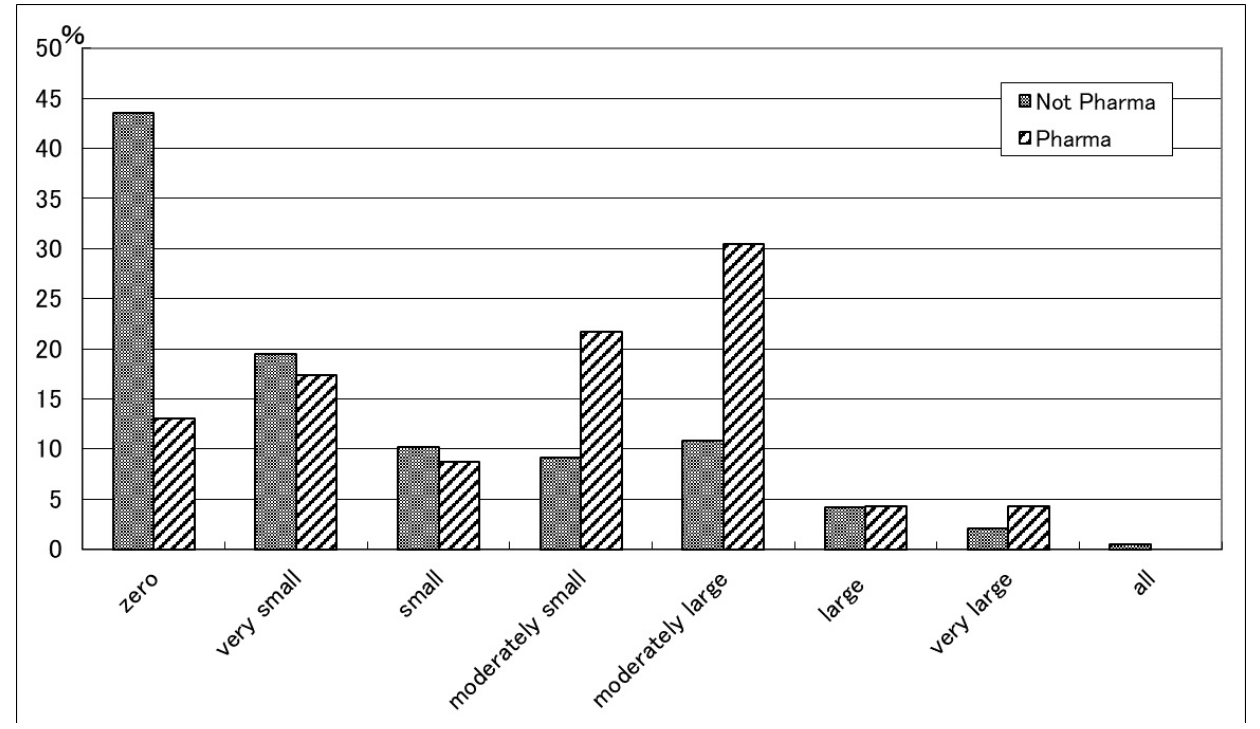

Figure 3. Evaluation of public research contributions to product innovation by managers: Comparison between non-pharmaceutical firms and pharmaceutical firms Pharmaceutical firms: $\mathrm{N}=23$; Non-pharmaceutical firms; $\mathrm{N}=5150$

(100\%), very large (more than $30 \%$ but less than $100 \%$ ), large (more than $10 \%$ but less than $30 \%$ ), moderately large (more than 3\% but less than 10\%), moderately small (more than $1 \%$ but less than $3 \%$ ), small (more than $0.3 \%$ but less than $1 \%$ ), very small (not zero but less than $0.3 \%)$, and zero $(0 \%)$. Fig. 2 shows the results for managers among all industries.

As seen in Fig. 2., an overwhelmingly large number of respondents selected 'zero' for the contribution extent of academic research, indicating that Japanese companies generally consider the potential contribution of academic knowledge to be of low value.

However, a review of the data by industry highlights interesting aspects of the findings. Fig. 3 distinguishes the results of pharmaceutical companies, a representative science-based industry, from those of others. Most pharmaceutical companies (23) answered 'moderately large', whereas most non-pharmaceutical companies $(5,150)$ answered 'zero'. In addition, the distribution of responses from non-pharmaceutical companies showed disproportionate weights for low evaluations ('moderately small', 'small', 'very small', and 'zero'), which was the expected result. Pharmaceutical companies, as part of a 'science-based industry', require scientific knowledge to produce new products. The closer companies are to science the higher their evaluation of academic research will be.
Note that most respondents were in management or general affairs divisions. Managers indirectly engage in R\&D, but may still fail to comprehend the basic research process leading to practical applications of resulting technology, even if they can evaluate commercialisation in the final stage. This may explain their low evaluations of research outcomes. However, inventors who engage in $R \& D$ understand precisely how basic research affects product innovation, and so they more fully appreciate the contribution of basic research to technological development. Therefore, we focused on inventors, specifically those in science-based industries.

\section{How do inventors evaluate the contribution of academic research outcomes?}

We asked inventors the same question as what was asked to the managers. Fig. 4 shows the distribution of respondents' evaluations of commercialisation based on public research outcomes. The distribution has two peaks: the most frequent response is 'very large', and the second most frequent is 'moderately large'. Compared with managers, the inventors we surveyed attached much higher value to product innovation based on the outcomes of public research.

As previously noted, inventors directly engage in $R \& D$. Therefore, they may have a better understanding of the importance of academic research for $R \& D$ than managers. Furthermore, as stated above, the closer a 


\section{Which Factors Influence a Company's Evaluation of the Contribution of Basic Research to Innovation? Hiromi S. Nagane \& Koichi Sumikura}

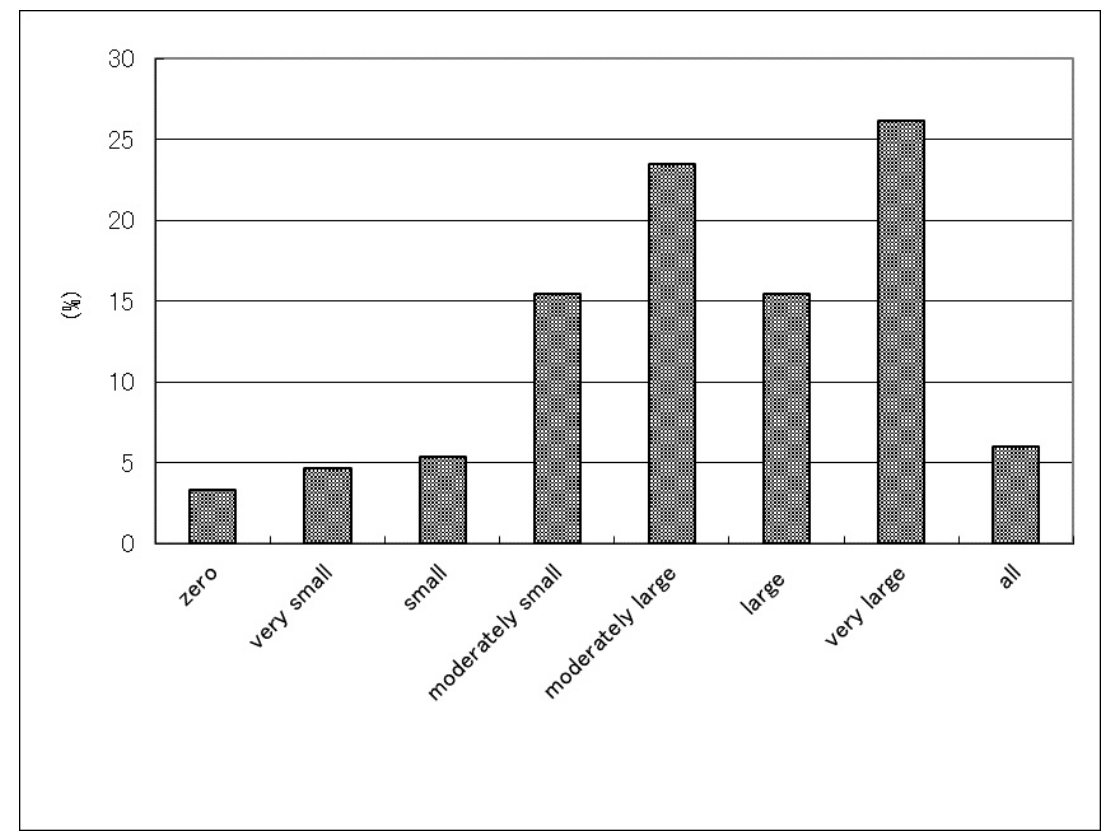

Figure 4. Evaluation of product innovation and market value based on public research by inventors $\mathrm{N}=148$

company is to science, the higher is likely to be its evaluation of academic research.

\section{Differences between inventors in large pharmaceutical companies and biotech start-ups}

We examined the variation in responses between inventors belonging to large companies and those belonging to biotech start-ups. We expected inventors from biotech start-ups to have higher evaluations of public research contributions to commercialisation than inventors from large companies. This was because some biotech start-ups originated out of public research, while large companies typically conduct research and develop products independently. However, this relationship was not necessarily evident in the analysis above. Moreover, differences were expected in terms of the importance of acquiring external knowledge between large pharmaceutical companies and biotech start-ups. We therefore examined whether inventors from biotech start-ups assigned a higher value to the contributions of public research to commercialisation than inventors from large companies.

Fig. 5 illustrates the distribution of responses. The black bar indicates the evaluations of inventors from large companies, while the light bar indicates evaluations of those from biotech start-ups.
The distribution of evaluations by inventors from large companies is slightly skewed to the right side of the diagram, but it is an approximately normal distribution. However, the distribution of evaluations by inventors from biotech start-ups is obviously skewed to the right. The results therefore confirm that inventors from biotech start-ups more highly evaluate the contribution of public research to commercialisation, compared with inventors from large companies.

\section{At which stage are academic research outcomes helpful} for companies?

We found that the degree of evaluating academic research contributions differed between inventors from large companies and those from start-ups. This difference might be due to how they use academic research. We thus examined how large pharmaceutical companies and biotech start-ups identified different uses of academic research outcomes. For the former, the purpose of research may be to produce new drugs, while for the latter, it may be to produce research tools. Our survey did not collect the necessary information to distinguish between these uses. However, we were led to assume that the stages at which large pharmaceutical companies and biotech start-ups use academic research outcomes differ, since their products differ significantly. In this regard, some questions asked in our survey were relevant for these evaluations. Each respondent was 


\section{Which Factors Influence a Company's Evaluation of the Contribution of Basic Research to Innovation? Hiromi S. Nagane \& Koichi Sumikura}

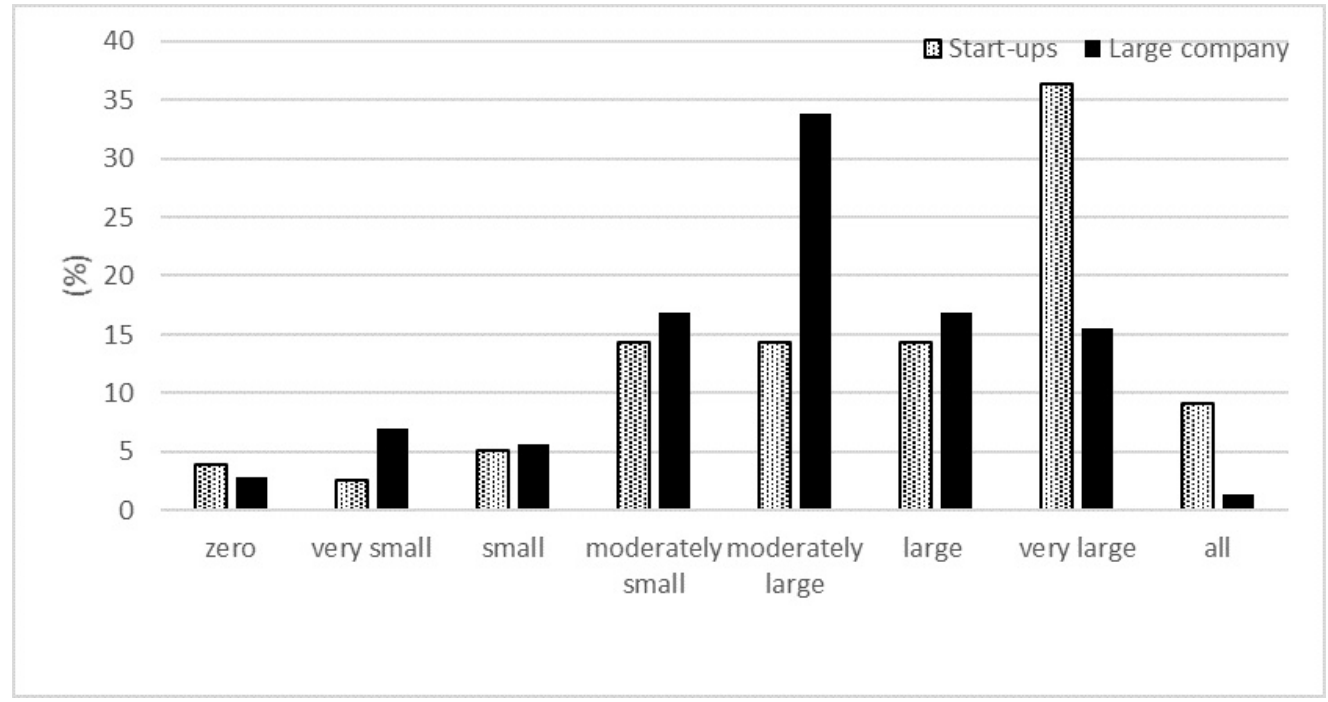

Figure 5. Evaluations of public research contributions to commercialisation: Large firm inventors vs. biotech start-up inventors

$\mathrm{N}=148$ (Large company: 71; Start-ups: 77)

asked, 'At which stage were research outcomes from universities and public research institutes helpful for your company?' Respondents could select from the 15 alternatives shown in Table 1. Fig. 6 shows the responses by affiliation.

The results demonstrate the similarities and differences between large pharmaceutical companies and biotech start-ups in their use of academic research outcomes. A test of statistical independence indicated that biotech start-ups utilised academic research outcomes more frequently than large pharmaceutical companies, with significant differences in Process 1 (Substitute for Basic Research), Process 7 (Confirmation of Effectiveness of Tech), and Process 12 (Complement for Merchandising). The results also showed that large pharmaceutical companies utilised academic research outcomes more frequently than biotech start-ups, with significant differences in Process 5 (Hint for Technological Problem-solving) and Process 9 (Enlightenment for R\&D Workers). Here, we note a tendency for biotech start-ups to utilise academic research outcomes directly as R\&D to substitute for their own basic research, while large pharmaceutical companies utilise them to indirectly support their R\&D, as enlightenment for workers.

\section{Which inventors highly evaluate public research} contributions to industry?

The above analysis did not identify the factors on which respondents base their evaluations of the contributions of public research to commercialisation. Although the outcomes of public research depend on multiple factors, we focused on whether inventors were affiliated with large companies or biotech start-ups. However, we acknowledge that the evaluation of public research also depends on other factors, for example, research experience and educational background. Furthermore, differences in evaluating the contributions of academic research outcomes to products may reflect differences in the stage at which the respondent utilises the outcome; alternatively, it may reflect other respondent factors. Therefore, an ordered probit (probability unit) model was used to control for these factors and to analyse how inventors' backgrounds affect their evaluations. The stages of use of academic research outcomes were also controlled for.

Eight order alternatives for commercialisation were taken as dependent variables. The ordered probit model was also used to analyse how public research outcomes enabled company performance. Eight ordered answers were proposed for the contribution to commercialisation as ordered variables. The model is given by:

$$
\begin{aligned}
& y_{i}^{*}=X_{i} a+e_{i} \quad e_{i} \sim N\left(0, s^{2}\right) \\
& y_{i}=j \quad \text { if } \quad \mu_{j-1} \leq y_{i}^{*} \leq \mu_{j}, \quad j=1, \ldots, J, \quad \mu_{0}=-\infty, \mu_{J}=+\infty
\end{aligned}
$$




\section{Which Factors Influence a Company's Evaluation of the Contribution of Basic Research to Innovation? Hiromi S. Nagane \& Koichi Sumikura}

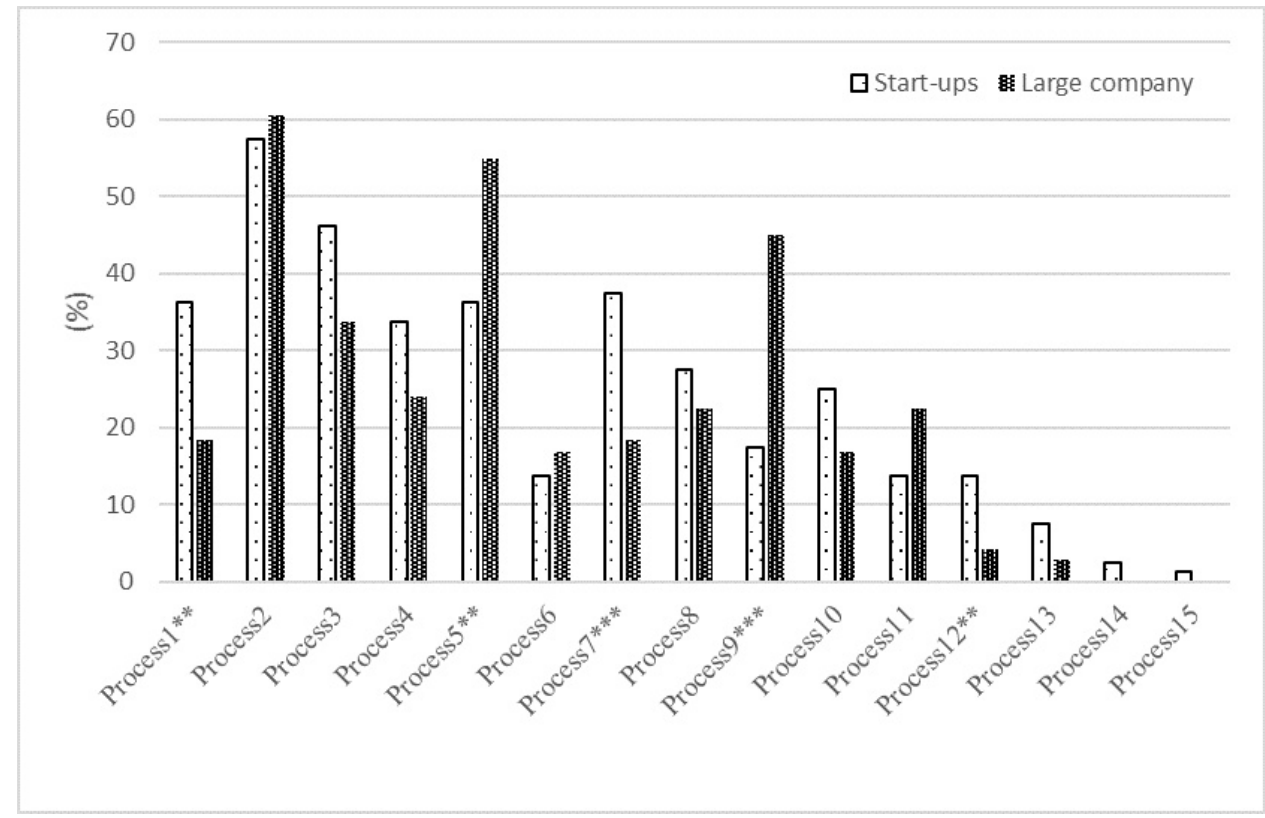

Figure 6. Stages at which academic research outcomes are helpful for firms' business by affiliation Test of independence: ${ }^{* *}$ significant at $5 \%$; ${ }^{* * *}$ significant at $1 \%$.

where $\mathrm{y}^{*} \mathrm{i}$ is an unobservable latent variable, and $\mathrm{y}_{\mathrm{i}}$ is an observable variable. $j$ corresponds to 8 if a respondent indicated 'all', 7 if 'very large', 6 if 'large', 5 if 'moderately large', 4 if 'moderately small', 3 if 'small', 2 if 'very small', and 1 if 'zero'. $a$ is a parameter. $X$ is a dummy variable for inventor background (see Table 1). We suppose that the error term $e_{i}$ exhibits a logistic distribution. However, Processes 14 and 15 were omitted from the independent variables because no pharmaceutical company answered 'yes' to them.

Table 2 below shows the estimation results for the contribution of academic research to products.

Both Wald tests were rejected. The baseline educational qualification is 'High/Junior high school'.

Model (1) controlled for only the basic attributes of inventors. In addition to these factors, Model (2) controlled for the stages of using academic research outcomes, excluding the affiliation with 'large company'. This was done to avoid an estimation bias resulting from the possibility that use stages depended on affiliation. In Model (3), all variables were controlled. The results for 'Research year', 'Ph.D.', 'Junior college', and 'Process 3 (Complement for Idea/Planning)' were found to be robust because they were significant in any models. However, 'junior college' does not have important implications in this study because only two participants were junior college graduates. Therefore, we excluded the result for 'junior college' here.

Our results indicate that inventors with extended research careers tended to assign low values to public research contributions, while inventors with a Ph.D. tended to assign high values. Inventors with a $\mathrm{Ph}$.D. are expected to understand the contents of advanced technology and thus appreciate the outcomes of public research. Further, inventors were found to assign high value to academic research outcomes when companies utilised them for aspects such as 'Complement for Idea/Planning'.

\section{Discussion}

This study found that:

1) Managers of pharmaceutical companies evaluate academic research more highly than other industries do.

2) Inventors evaluate academic research more highly than managers in pharmaceutical companies or biotech start-ups.

3) Inventors from start-ups evaluate academic 
Which Factors Influence a Company's Evaluation of the Contribution of Basic Research to Innovation? Hiromi S. Nagane \& Koichi Sumikura

Table 2. Estimation by ordered probit model based on 'Product'

\begin{tabular}{|c|c|c|c|c|c|c|c|c|c|c|c|c|}
\hline & & (1) & & & & (Z) & & & & (3) & & \\
\hline & Coef. & SE. & Z-vilue & & Coef. & SE & Z-value & & Coef. & SE & Z-volue & \\
\hline Late company & -0.45 & 0.21 & -218 & $\#$ & & & & & -031 & 0.24 & -1.27 & \\
\hline Research year & -0.04 & 0.01 & -248 & $\approx$ & -0.04 & 0.01 & -3.34 & 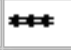 & -0.03 & $\mathbf{0 . 0 2}$ & -227 & $\neq$ \\
\hline FhD. & 0.96 & 0.45 & 215 & $*$ & 059 & 0.31 & 1.92 & $*$ & 0.77 & 034 & 229 & $\Rightarrow$ \\
\hline HA & 039 & 0.46 & 0.85 & & $\mathbf{0 . 1 3}$ & 0.31 & 0.42 & & 0.33 & 0.35 & 0.94 & \\
\hline B.A. & -0.53 & 0.51 & -1.04 & & -0.75 & 0.43 & -1.74 & $*$ & -0.68 & 0.45 & -152 & \\
\hline Junior college & 1.19 & 0.47 & 254 & $\approx$ & 1.42 & 0.38 & 3.71 & $\neq$ & 156 & 0.41 & 3.8 & 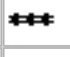 \\
\hline Tertiery college & -0.29 & 0.69 & -0.41 & & 0.50 & 0.95 & 0.52 & & -0.28 & 0.64 & -0.43 & \\
\hline Corer college & 150 & L.00 & 1.5 & & 105 & 1.07 & 0.98 & & 1.34 & 105 & 1.27 & \\
\hline Processi 1 & & & & & 031 & 0.24 & 1.33 & & 0.22 & 0.24 & 0.95 & \\
\hline Process? & & & & & -0.11 & 0.19 & -0.56 & & -0.03 & 0.19 & -0.17 & \\
\hline Process 3 & & & & & 0.41 & 0.21 & 1.92 & $*$ & 038 & 0.22 & 1.74 & $*$ \\
\hline Processt & & & & & 0.09 & 0.21 & 0.42 & & 0.09 & 0.21 & 0.44 & \\
\hline Procers 5 & & & & & -0.21 & 0.18 & -1.19 & & -0.12 & 0.18 & -0.64 & \\
\hline Processot & & & & & -0.16 & 0.26 & -0.6 & & -0.20 & 0.27 & -0.76 & \\
\hline Process? & & & & & 030 & 0.19 & 159 & & 0.26 & 0.20 & 1.34 & \\
\hline Procerse8 & & & & & 0.13 & 0.19 & 0.67 & & 0.20 & 0.20 & 0.96 & \\
\hline Processes & & & & & 0.02 & 0.18 & 0.08 & & 0.01 & 0.19 & 0.07 & \\
\hline Process 10 & & & & & -0.11 & 0.24 & -0.48 & & -0.15 & 0.25 & -0.61 & \\
\hline Procersil & & & & & -0.14 & 0.21 & -0.65 & & -0.03 & 0.23 & -0.15 & \\
\hline Process 12 & & & & & 0.42 & 0.35 & 1.23 & & 0.36 & 0.36 & 1 & \\
\hline Process 13 & & & & & -0.54 & 0.51 & -1.05 & & -0.54 & 0.55 & -0.99 & \\
\hline cot1 & -247 & 0.57 & & & -249 & 0.55 & & & -236 & 0.57 & & \\
\hline $\cot 2$ & -1.85 & 0.52 & & & -1.88 & 0.49 & & & -1.72 & 0.51 & & \\
\hline $\cot 3$ & -1.45 & 0.49 & & & -150 & 0.46 & & & -1.33 & 0.48 & & \\
\hline cot4 & -1.880 & 0.47 & & & -0.83 & 0.45 & & & -0.65 & 0.47 & & \\
\hline cos & -0.05 & 0.47 & & & -0.05 & 0.43 & & & 0.14 & 0.46 & & \\
\hline cot6 & 0.46 & 0.46 & & & 0.49 & 0.43 & & & 0.69 & 0.45 & & \\
\hline $\cot 7$ & 1.84 & 050 & & & 1.85 & 0.45 & & & 213 & 0.48 & & \\
\hline Ohs: & 140 & & & & 141 & & & & 140 & & & \\
\hline Pseodo R2 & D.AB & & & & 0.10 & & & & 0.11 & & & \\
\hline Losperodolikelihood & -234.36 & & & & -23257 & & & & -228.03 & & & \\
\hline
\end{tabular}

research more highly than inventors from large companies in the pharmaceutical industry or biotech start-ups.

4) $\mathrm{Ph} . \mathrm{D}$. holders evaluate academic research more highly than inventors without a Ph.D.

We therefore suggest that the closer a business person is to science the higher his or her evaluation of the contributions of academic research will be. Fig. 7 shows the relationship between closeness to science and evaluation of academic research.

Based on these results, we examined the 'health' or 'sickness' of innovation in Japan. As mentioned, the basic research sector has recently diminished in Japan. 


\section{Which Factors Influence a Company's Evaluation of the Contribution of Basic Research to Innovation? Hiromi S. Nagane \& Koichi Sumikura}

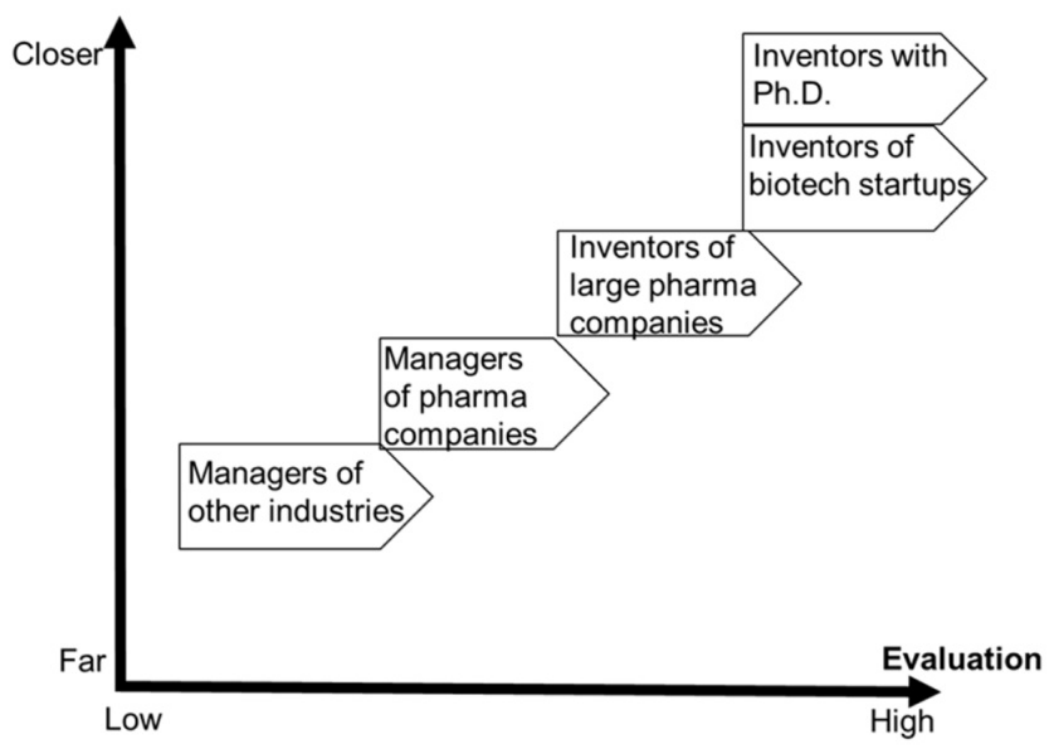

Figure 7. Relationship between evaluation of contributions of academic research and closeness to science

This is true for industry as well as for universities and public research institutes. The level of basic research that is important for innovation, however, is still unknown. One reason may be due to Japan's specific organizational structure. In Japan, many officer-class executives graduate from liberal arts courses (Toyokeizai, 2018), and those without a natural science background may not understand the importance of basic research. Moreover, there is little interaction between the liberal arts and natural sciences domains in Japan, as also between managers and inventors.

Furthermore, the Japanese educational system requires students to choose a single program - 'liberal arts' or 'natural science' - at an early stage, during first year in university or high school. Many countries have similar systems to this, but, in Japan, there are few opportunities for students to interact with both fields after graduation. This 'division' leads to a basic problem in technology management. The roles are fixed: individuals from liberal arts backgrounds are managers, while those from natural science backgrounds conduct R\&D. We believe to overcome this gap in communication that platforms should be created where individuals from these backgrounds can communicate with one another. Furthermore, the educational system in Japan should be reformed to enable more interdisciplinary interaction. We believe that the curriculum should be re-designed in order to facilitate the study of both liberal arts and natural sciences, at least at some level, for all Japanese students.

\section{Conclusion}

This study concluded that 'closeness to science' is important to companies' evaluations of the contributions of basic research to innovation. It found that 1) the more science-oriented the company, the higher the evaluation of academic research by managers, 2) inventors evaluate academic research more highly than managers, 3) inventors from biotech start-ups evaluate academic research more highly than inventors from large companies in the pharmaceutical industry, and 4) the more advanced their educational background, the more highly inventors evaluate academic research. This study suggests that the closer individuals in companies are to either doing or understanding science, the higher will be their evaluations of the contributions of academic research.

Existing literatures have already empirically studied the impact of basic research on industry. However, most studies have based their evaluations on formal outcomes, such as papers and patents. In contrast, this study contributed to existing literature in that it empirically gave shape to a potential evaluation for basic research.

What is the importance of these findings? When basic research outcomes are transferred from university and 


\section{Which Factors Influence a Company's Evaluation of the Contribution of Basic Research to Innovation? Hiromi S. Nagane \& Koichi Sumikura}

public research institutes to industries, companies can create breakthrough technologies as well as new products and services. If companies lack talent that can adequately discern and evaluate academic research, engagement with external basic research outcome stagnates. Companies generally separate workplaces, however, between management and R\&D departments. If companies were to help educate managers in properly evaluating the value of basic research, or assign individuals to advise managers on technology, it could help companies induce basic research outcomes.

The Japanese educational system divides students into 'liberal arts' and 'natural sciences' programs at an early stage, in high school, or in the first year of university. For this reason, technology management programs that have recently developed in university graduate schools could end up playing a significant role in Japan.

This study used survey data in Japan. However, we suppose that it is possible to generalize the results if a similar survey were to be conducted in other countries. This is an issue for the future.

This study has some limitations. First, we could have additionally introduced qualitative methods, such as case studies or interviews, along with the quantitative approach. Furthermore, interviewing managers and inventors belonging to the same company would significantly enhance the research insights. Second, while this paper focuses on Japan, the research can be extended in the future to include other countries. This would serve to provide a way to verify whether our results extend to other countries as well.

\section{References}

Bush, V. 1945. Science: The endless frontier. United States Government Printing Office, Washington. Accessed 13 June 2020:

https://www.nsf.gov/od/lpa/nsf50/vbush1945.htm

Chesbrough, H.W. 2003. Open Innovation: The new imperative for creating and profiting from technology. Boston: Harvard Business School Press.

Chesbrough, H.W. 2006. Open Business Models: How to thrive in the new innovation landscape. Boston: Harvard Business School Press.

Cockburn, I., \& Henderson, R. 1998. Public-private interaction and the productivity of pharmaceutical research. NBER Working Paper Series, No. 6018. Accessed February 2020:

https://www.nber.org/papers/w6018

De Fuentes, C., \& Dutrénit, G. 2016. Geographic proximity and university-industry interaction: The case of Mexico. Journal of Technology Transfer, 41: 329348.

Fernandez-Esquinas, M., Pinto, H., Yruela, M.P., \& Pereira, T.S. 2016. Tracing the flows of knowledge transfer: Latent dimensions and determinants of university-industry interactions in peripheral innovation systems. Technological Forecasting and Social Change, 113: 266-279.

IMS. (n.d.). IMS pharmaceutical market statistics. Retrieved from

http://www.ims-japan.co.jp/docs/top_line_08YE.pdf

Jaffe, A.B. 2006. The 'Science of science policy': Reflections on the important questions and the challenges they present. Keynote address: NSF workshop on advancing measures of innovation: Knowledge flows, business metrics, and measurement strategies. Accessed 2/4/2018:

http://people.brandeis.edu/ ajaffe/PAPER\%20\%20science\%20of\%20science\%20policy.pdf sfield, E. 1991. Academic research and industrial innovation. Research Policy, 20: 1-12. https://doi.org/10.1016/0048-7333(91)90080-A

Mansfield, E. 1998. Research and industrial innovation: An update of empirical findings. Research Policy, 26: 773-776. https://doi.org/10.1016/0048-7333(91)90080-A

McMillan, G.S., Narin, F., \& Deeds, D.L. 2000. An analysis of the critical role of public science in innovation: The case of biotechnology. Research Policy, (29): 1-8. https://doi.org/10.1016/S0048-7333(99)00030-X.

Narin, F., Hamilton, K. S., \& Olivastro, D. 1997. The increasing linkage between U.S. technology and public science. Research Policy, 26: 317-330. https://doi.org/10.1016/S0048-7333(97)00013-9. 


\section{Which Factors Influence a Company's Evaluation of the Contribution of Basic Research to Innovation? Hiromi S. Nagane \& Koichi Sumikura}

NISTEP. 2019. Digest of Japanese science and technology indicators 2019. Research material-283. Accessed 13/06/2020: https://www.nistep.go.jp/wp/wpcontent/uploads/NISTEP-RM283-SummaryE.pdf

OECD. 2002. OECD Frascati Manual, Sixth edition.

Patent Result Co., Ltd. (n.d.). Patent Score. (In Japanese). Accessed 2/4/2018:

http://www.patentresult.co.jp/aboutpatentscore.html

Rosenbloom, R.S., \& Spencer, W.J. 1996. Engines of Innovation. Boston: Harvard Business School Press.

Saito, H., \& Sumikura, K. 2010a. An empirical analysis of absorptive capacity based on linkage with academia. International Journal of Innovation Management, 14(3): 491-509.

https://doi.org/10.1142/S1363919610002751

Saito, H., \& Sumikura, K. 2010b. How are the fruits of research in universities and public research institutes used? A brief overview from the GRIPS firm survey. GRIPS Discussion Paper Series 10-15. Retrieved from: http://www3.grips.ac.jp/ pinc/data/10-15.pdf

Sumikura, K., \& Saito, H. 2016. How can we promote the development of new drugs from academic knowledge? Focusing on the corporate perspective on the contribution of basic research to innovation. Proceedings of PICMET 2016.

Stevens, A. J., Jensen, J.J., Wyller, K., Kilgore, P.C., Chatterjee, S., \& Rohrbaugh, M.L. 2011. The role of public-sector research in the discovery of drugs and vaccines. New England Journal of Medicine, 364(6): $535-541$

TOYOKEIZAI online. 2018. The ranking of 'The rate is high at which officers graduate from natural science' 500 companies. (In Japanese). Accessed 13/6/2020: https://toyokeizai.net/articles/print/234119

Zucker, L.G., \& Darby, M.R. 2001. Capturing technological opportunity via Japan's star scientists: Evidence from Japanese firms' biotech patents and products. Journal of Technology Transfer, 26(1-2): 3758.

https://doi.org/10.1023/A:1007832127813

Zucker, L.G., \& Darby, M.R. 2007. Virtuous circles in science and commerce. Papers in Regional Science, 86(3): 445-470.

https://doi.org/10.1111/j.1435-5957.2007.00133.x

Zucker, L.G., Darby, M R., \& Armstrong, J. S. 2002. Commercializing knowledge: University science, knowledge capture, and firm performance in biotechnology. Management Science, 48(1): 138-153. https://doi.org/10.1287/mnsc.48.1.138.14274

\section{About the Authors}

Hiromi S. Nagane is Professor of Graduate School of Social Sciences at the Chiba University in Japan. She earned her Ph.D. in Economics from Hitotsubashi University. Her research interests are health economics, economics of innovation, science and technology policy, higher education policy, and industry-academia collaboration. She has published articles about health regulations, the relation between firms' performance and absorptive capacity, the productivity of academic articles, leading scientists, and so on. She also received a category award for her article about science and technology policy from the Japan Society of Mechanical Engineers in 2020. She holds the post of visiting scholar of the National Institute of Science and Technology Policy (NISTEP) of the Ministry of Education, Culture, Sports, Science and Technology (MEXT).

Koichi Sumikura is Deputy Director, GiST Program, GRIPS Professor. He earned his Ph.D. from the University of Tokyo Graduate School for Engineering in 1998 and is now a visiting assistant at the University of Tokyo's Research Unit. His specialty is in intellectual property rights, bio-technology, and industry-academia collaboration. $\mathrm{He}$ is a visiting scholar of NISTEP.

Citation: Nagane, H.S., and Sumikura, K. 2020. Which Factors Influence a Company's Evaluation of the Contribution of Basic Research to Innovation? Technology Innovation Management Review, 10(8): 38-51. http://doi.org/10.22215/timreview/1380

Keywords: Basic research, University and Public research institute, Innovation, Pharmaceutical companies, Biotech start-ups. 